Note

\title{
A SIMPLE DEVICE IN A HORIZONTAL TG ANALYZER TO PREVENT MIXING OF CORROSIVE AND PROTECTIVE GASES
}

\author{
G.M.H. VAN DE VELDE, T.A. LONGE* and U. SPITSBERGEN \\ Department of Chemical Engineering. Twente University of Technologi, P.O. Box 217, 7500 AE \\ Enschede (The Netherlands)
}

(Received 14 December 1981)

A ceramic cylinder has been developed as an accessory to a standard DuPont 951 Thermogravimetric Analyzer to study weight changes of solid samples in corrosive atmospheres.

This device has two purposes to be fulfilled at higher temperatures $\left(\leqslant 900^{\circ} \mathrm{C}\right)$ and higher gas flow rates $\left(\leqslant 14 \mathrm{~cm} \mathrm{~s}^{-1}\right)$ : (1) preventing mixing of reactant and purge gases at the location of the sample; and (2) keeping the corrosive reactant gas from the balance sections.

\section{EXPERIMENTAL}

For corrosive atmospheres such as nitrogen mixtures with sulphur dioxide etc., the instruction manual of the DuPont 951 Thermogravimetric Analyzer [1] advises the installation of a gas inlet tube on the furnace tube between the furnace and the balance housing. A stopcock is sealed to the pyrex bell jar to purge the back end of the balance assembly. The normal gas inlet. located on the balance housing, is also flushed :vith the inert gas. The reactive gas is admitted through the side arm of the furnace tube so that it will flow to the sample along with the purge gas.

The main disadvantage of this system is that the purge gas mixes with the reactant gas around the sample making it difficult to establish a constant and reproducible concentration of the latter. To avoid this, we worked with a different modification. This does not require a complicated double furnace tube, as described by Ruth et al. [2] and Ulerich et al. [3].

The reactive gas mixture is adnitted from the end (Fig. 1) and leaves the sample housing through the side arm, which now has the function of outlet. The extra furnace tube $l$ as a preheater is necessary to establish selected high

\footnotetext{
* Present address: Department of Chemical Engineering, Ahmadu Bello University, Zaria. Nigeria.
} 


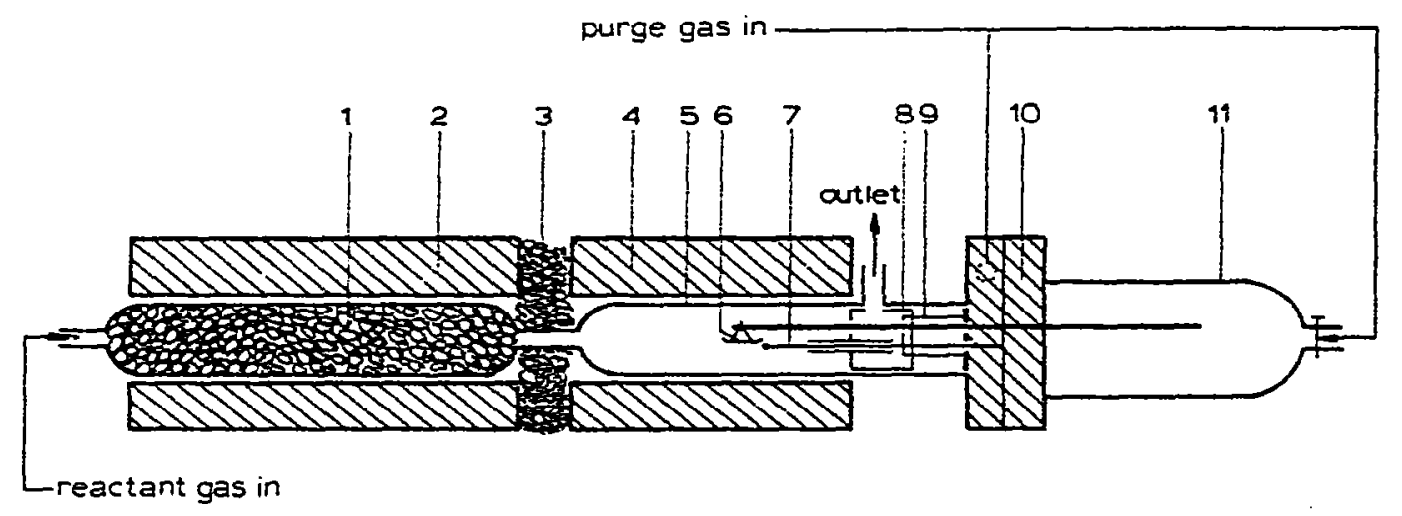

Fig. 1. Modified DuPont TG apparatus. 1, Crushed alumina: 2, preheater furnace; 3, quartz wool; 4. reactor fumace; 5 , quartz tube; 6 , sample pan: 7 sample thermocouple; 8 , ceramic cylinder; 9 , beam sheath; 10 , balance housing; 11 , pyrex bell jar.

temperatures at high gas flow rates. The essential part of the modification is a detachable accessory, an alumina cylinder, which works as an effective obstacle against the mixing of inert purge and reactant gases around the sample. The cylinder is supported by the metal beam sheath of the balance (which fits into the incision I of the cylinder Fig. 2) and by the extra alumina tube around the metal thermocouple protection.

A ceramic disc $F$, at the front end of the cylinder, provides separation between the reaction and balance zones. The small slots $S$ and $T$ in the disc
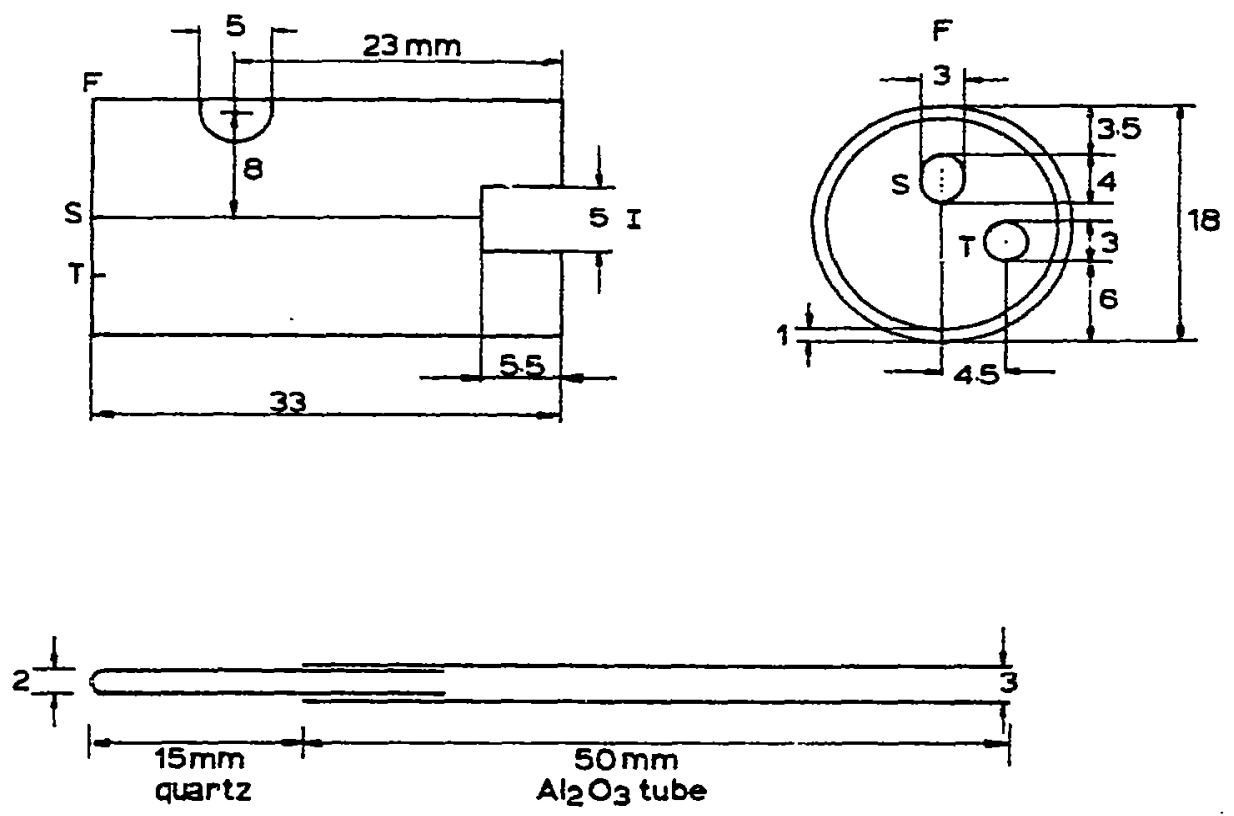

Fig. 2. Details of the ceramic cylinder, two-hole disc and thermocouple protection. 
provide a passage for the quartz balance rod and the thermocouple tube. At the thermocouple end of the extra alumina tube a thinner quartz tube (diameter $2 \mathrm{~mm}$ ) can be connected to protect the thermocouple itself. Some quartz wool can be put into the open end of the cylinder to hold it more firmly supported on the beam sheath. The purge gas, e.g. nitrogen, flows through the balance housing and the extra stopcock of the bell jar into the beam sheath. A hole on the side of the ceramic cylinder (adjacent to the side arm) permits the outflow of purge gas. Both the purge and reactant gases leave the furnace tube through the side arm.

The efficiency of the modification was tested by means of copper powder (reduced by hydrogen) in the sample pan, nitrogen as the gas in the furnace tube and oxygen as the purge gas in bell jar and balance housing. The weight gain by oxidation of the sample at $600^{\circ} \mathrm{C}$ was taken to be indicative of purge gas penetration. This was found to depend on the ratio of the purge to reactant gas and the flow rate of the reactant gas (in the case of the copper experiments actually inert, the purge gas in the balance housing being oxygen).

For instance, at reactant gas velocity of $14 \mathrm{~cm} \mathrm{~s}^{-1}$ ( $1 \mathrm{bar}$ ) and purge to reactant gas flow ratio of 1:6 gas mixing was found to be negligible. At ratio $1: 2$ and velocity of $8 \mathrm{~cm} \mathrm{~s}^{-1}$ the oxidation weight increase was found to be $0.025 \%$. In our circumstances no weight increase for atmosphere-sensitive substances, put at the bottom of the bell jar, was detected, so the balance housing was sufficiently protected. The modified TG apparatus was used for the comparison of European limestones on their sulphur retention efficiencies. The results of these TG experiments were in agreement with those of other testing methods, a selection of which has been described [4].

\section{REFERENCES}

1 DuPont Instruments, Instruction Manual 990 Thermal Analyzer and Modules, Sect. 9, 1976.

2 L.A. Ruth, A.M. Squires and R.A Graff, Environ. Sci. Technol., 6 (1972) 1009.

3 N.H. Ulerich, R.A. Newby and D.L. Keairns, Thermochim. Acta, 36 (1980) 1.

4 U. Spitsbergen, Ch. J. Vincent and T.A. Longe, J. Inst. Energy, 54 (1981) 94. 